\title{
EMS non-conveyance: A safe practice to decrease ED crowding or a threat to patient safety?
}

\author{
Jani Paulin ${ }^{1 *}\left(\mathbb{D}\right.$, Jouni Kurola ${ }^{2}$, Mari Koivisto ${ }^{3}$ and Timo lirola ${ }^{4}$
}

\begin{abstract}
Background: The safety of the Emergency Medical Service's (EMS's) non-conveyance decision was evaluated by EMS re-contacts, primary health care or emergency department (ED) visits, and hospitalization within $48 \mathrm{~h}$. The secondary outcome was 28-day mortality.

Methods: This cohort study used prospectively collected data on non-conveyed EMS patients from three different regions in Finland between June 1 and November 30, 2018. The Adjusted International Classification of Primary Care (ICPC2) as the reason for care was compared to hospital discharge diagnoses (ICD10). Multivariable logistic regressions were used to determine factors that were independently associated with adverse outcomes. Results are presented with adjusted odds ratios (aORs) together with 95\% confidence intervals (Cls). Data regarding deceased patients were reviewed by the study group.

Results: Of the non-conveyed EMS patients $(n=11,861), 6.3 \%$ re-contacted the EMS, $8.3 \%$ attended a primary health care facility, $4.2 \%$ went to the ED, 1.6\% were hospitalized, and $0.1 \%$ died $0-24 \mathrm{~h}$ after the EMS mission. The 0-24 $\mathrm{h}$ adverse event rate was higher than 24-48 h. After non-conveyance, $32(0.3 \%)$ patients were admitted to an intensive care unit within $24 \mathrm{~h}$. Primary non-urgent EMS mission (aOR 1.49; 95\% Cl 1.25 to 1.77), EMS arrival at night (aOR 1.82; $95 \% \mathrm{Cl} 1.58$ to 2.09), ALS unit type vs BLS (aOR 1.43; $95 \% \mathrm{Cl} 1.16$ to 1.77), rural area (aOR 1.74; $95 \% \mathrm{Cl} 1.51$ to 1.99$)$, and older patient age (aOR $1.41 ; 95 \% \mathrm{Cl} 1.20$ to 1.66) were associated with subsequent primary health care visits (0-24 h).
\end{abstract}

Conclusions: Four in five non-conveyed patients did not have any re-contact in follow-up period. EMS nonconveyance seems to be a relatively safe method of focusing ED resources and avoiding ED crowding.

Keywords: Emergency medical service, Non-conveyance, Adverse outcome, Patient safety

\section{Background}

Emergency Medical Services (EMSs) and emergency departments (EDs) have reported increased workload [1, 2], mainly due to an aging population and difficulties accessing primary care [2]. The role of the EMS has changed to include more non-critical emergency patients

\footnotetext{
*Correspondence: jani.paulin@utu.fi

'Department of Clinical Medicine, University of Turku and Turku University of Applied Sciences, Turku, Finland

Full list of author information is available at the end of the article
}

[3], and patients are increasingly assessed and treated at the scene by EMSs, avoiding unnecessary conveyance to EDs [4]. Reported non-conveyance rates substantially vary internationally, between 3.7 and $93.7 \%$ in the general population [5]; in Finland, the rate is approximately $40 \%[3,6,7]$.

The decision-making process for non-conveyance appears to be complex and multifactorial [5]. EMS care providers' higher education level [3, 8], EMS arrival time in the evening or at night $[3,7,9,10]$, longer distance to

(c) The Author(s). 2021 Open Access This article is licensed under a Creative Commons Attribution 4.0 International License, which permits use, sharing, adaptation, distribution and reproduction in any medium or format, as long as you give appropriate credit to the original author(s) and the source, provide a link to the Creative Commons licence, and indicate if changes were made. The images or other third party material in this article are included in the article's Creative Commons licence, unless indicated otherwise in a credit line to the material. If material is not included in the article's Creative Commons licence and your intended use is not permitted by statutory regulation or exceeds the permitted use, you will need to obtain permission directly from the copyright holder. To view a copy of this licence, visit http://creativecommons.org/licenses/by/4.0/ The Creative Commons Public Domain Dedication waiver (http://creativecommons.org/publicdomain/zero/1.0/) applies to the data made available in this article, unless otherwise stated in a credit line to the data. 
a healthcare facility [7], rural area, younger patient age $[3,10,11]$, low National Early Warning Score (NEWS2), and alcohol use increase the likelihood of nonconveyance [3]. A recent review showed that, after a non-conveyance decision, re-contact with the EMS or the ED, hospitalization and mortality rates varied a lot [5]. However, whether re-contact with EMS was for a similar reason as the initial EMS contact is unclear [5].

Assessment and triage are a central part of the EMS work process [4]. Under-triaging may put patients' safety at risk, whereas over-triaging leads to inappropriate use of limited resources [12]. NEWS2 developed by the Royal College of Physicians is a simple, widely adopted scoring system [13]. NEWS2 may help identify patients at risk of deterioration who need to be treated and conveyed by the EMS, but whether it can be used as an indicator regarding EMS non-conveyance decisions is controversial [14, 15].

Patient safety is a priority of the EMSs. Decisions not to convey patients may represent a risk to patient safety. These safety factors are unclear in the prehospital setting $[4,16]$ and relevant studies are lacking $[5,17]$. However, some studies indicate that EMSs are able to make accurate preliminary diagnoses [18]. In the EMS context, a great number of adverse outcomes are associated with difficulties in clinical judgement [16] and patient groups with non-specific reasons for care $[19,20]$. Older age and abnormal vital signs are common predictors of adverse outcomes after non-conveyance and, therefore, pose a threat to patient safety [21]. Finally, from the patient safety perspective, little is known about nonconveyance decisions and related adverse outcomes [5, $17,22]$.

The aim of this study was to identify the rate and predictors of adverse outcomes after non-conveyance by the EMSs to determine whether the current practice of nonconveyance ensures patient safety.

\section{Methods}

Design

This is a prospective cohort study.

\section{Finland's health care system and EMS}

Finland is one of the five Nordic welfare states. The health care system is financed by public funds and mainly organized by public sector. Health services are divided into primary and specialized medical care.

Organized by 21 hospital districts, EMSs are part of specialized care. In a four-tiered system, ambulance units are normally at the ALS level manned by at least one paramedic-nurse with a 4-year bachelor-level education. The other person in an ALS unit or personnel in a BLS unit can be a firefighter, an emergency medical technician (EMT) or a practical / registered nurse. A non-conveyance decision can be made supported by regional or national guidelines or by consulting a $24 / 7$ oncall EMS or primary care physician. If EMS conveyance is needed, the target ED or other health care facility is decided upon by the EMS care provider with consultation of the EMSs or primary care physician if necessary [23].

A national dispatch authority operates with the common 112 emergency number in six regional emergency medical communication centers (EMCCs). Medical emergency calls are classified into four categories (A, B, $C$, and $D$ ), with $A$ and $B$ being urgent calls with lights and sirens. All dispatchers have completed 18 months of education, but they are usually not health care providers.

\section{The EMS data}

The EMS data were collected between June 1 and November 30, 2018, from the data systems of the Finnish hospital districts of South-Savo, Kanta-Häme, and Päijät-Häme (Fig. 1). The study area, consisting of 32 municipalities and both urban and rural areas, has 482,805 inhabitants, which is $8.8 \%$ of the total Finnish population. The average population density is 26.1 people per square kilometer. The adjusted ICPC2 classification as the main reason for EMS care was taken in to use. The original ICPC2 coding is used in primary care and published by WHO [24, 25]. The adjusted classification (around one hundred ICPC2 codes) was created by the Nordic Collaboration (Benchmarking) Group for the context of prehospital emergency care [26] and it is published in the code server of the Finnish Institute for Health and Welfare [27]. The EMS care providers were trained in the use of the codes before the study period. More detailed description of the adjusted ICPC2 classification, measurement and interpretation of the NEWS2 scores, urban-rural classification, distance to health care facilities, use of alcohol, and additional data collection were described previously [3].

\section{Study protocol}

Non-conveyed patients who were discharged at the scene after EMS assessment and treatment were included in this analysis. Exclusion criteria are presented in Fig. 2. Included patients were identified using unique 10-digit personal identity numbers and linked to the registries described below.

The first EMS re-contact was recorded between 0 and $24 \mathrm{~h}$ and $24-48 \mathrm{~h}$ from the initial non-conveyance EMS mission. If the re-contact did not lead to conveyance, a new follow-up period was started. The main reason for care (ICPC2; preliminary diagnosis) was compared between the initial contact and the EMS re-contact, i.e., whether the re-contact was related to the initial nonconveyance mission. 


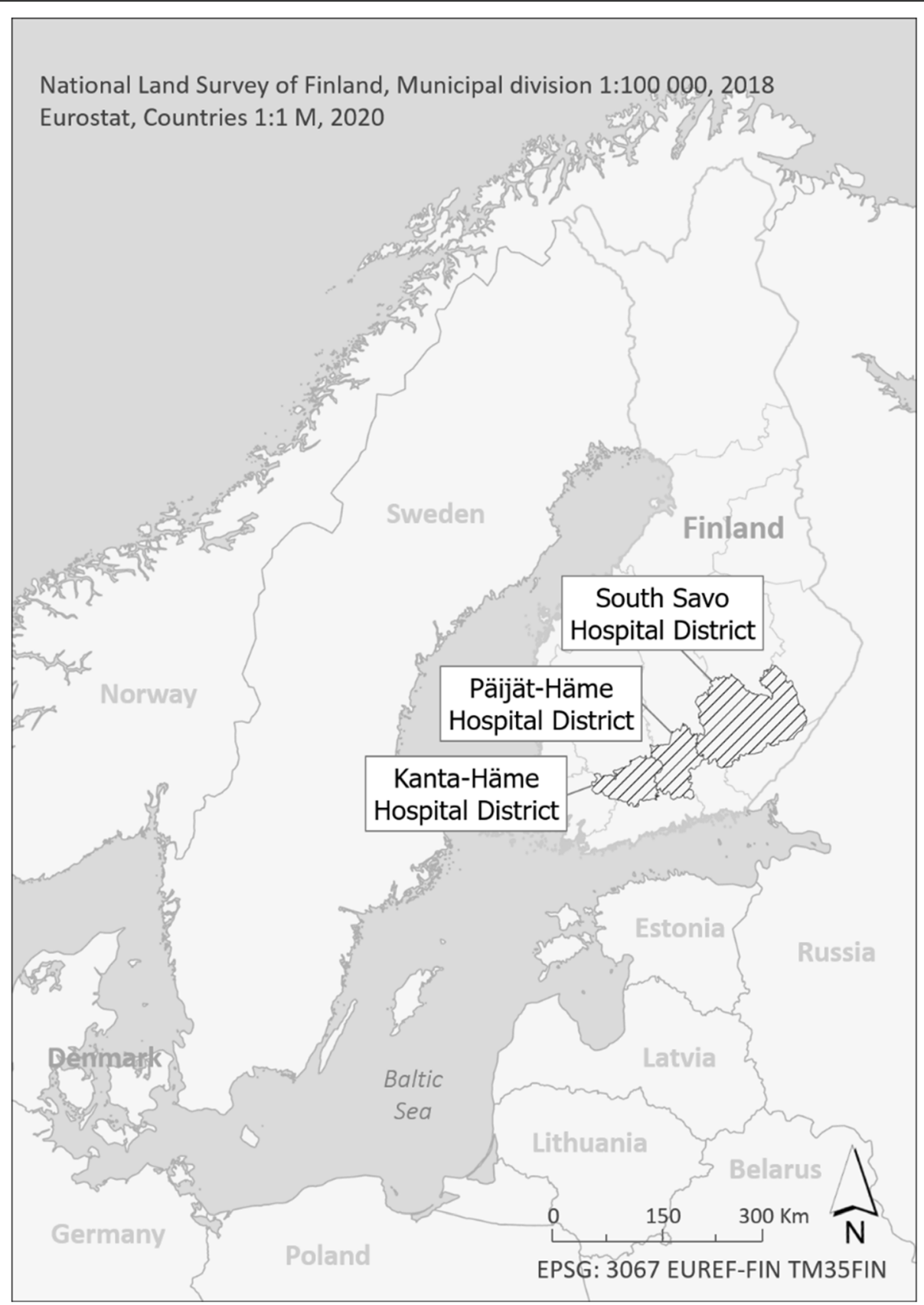

Fig. 1 Study areas

In Finland, hospital districts are required to submit care notifications to registries. Therefore, registry information on visits to primary health care facilities or EDs and hospitalization is available from the Finnish Institute for Health and Welfare [28, 29]. Unscheduled visits to primary health care and EDs $(0-24 \mathrm{~h}$ or $24-48 \mathrm{~h}$ ) were collected. If the exact time of the visit was missing, the initial non-conveyance case was judged to have occurred first and the $0-24 \mathrm{~h}$ health care visit to have occurred the same day or the day after. However, in the Register of Primary Health Care Visits [28], the data also include chronic disease monitoring. The first visit was analyzed and combined with the latest non-conveyance case if there were many. Whether the patient went to hospital by ambulance or by other means was not recorded. The ICPC2 code chosen by the EMS was compared to the main discharge diagnosis (ICD10) based on ICPC2 and ICD10 mapping charts to determine whether the visit was for the same or a related complaint [25]. 


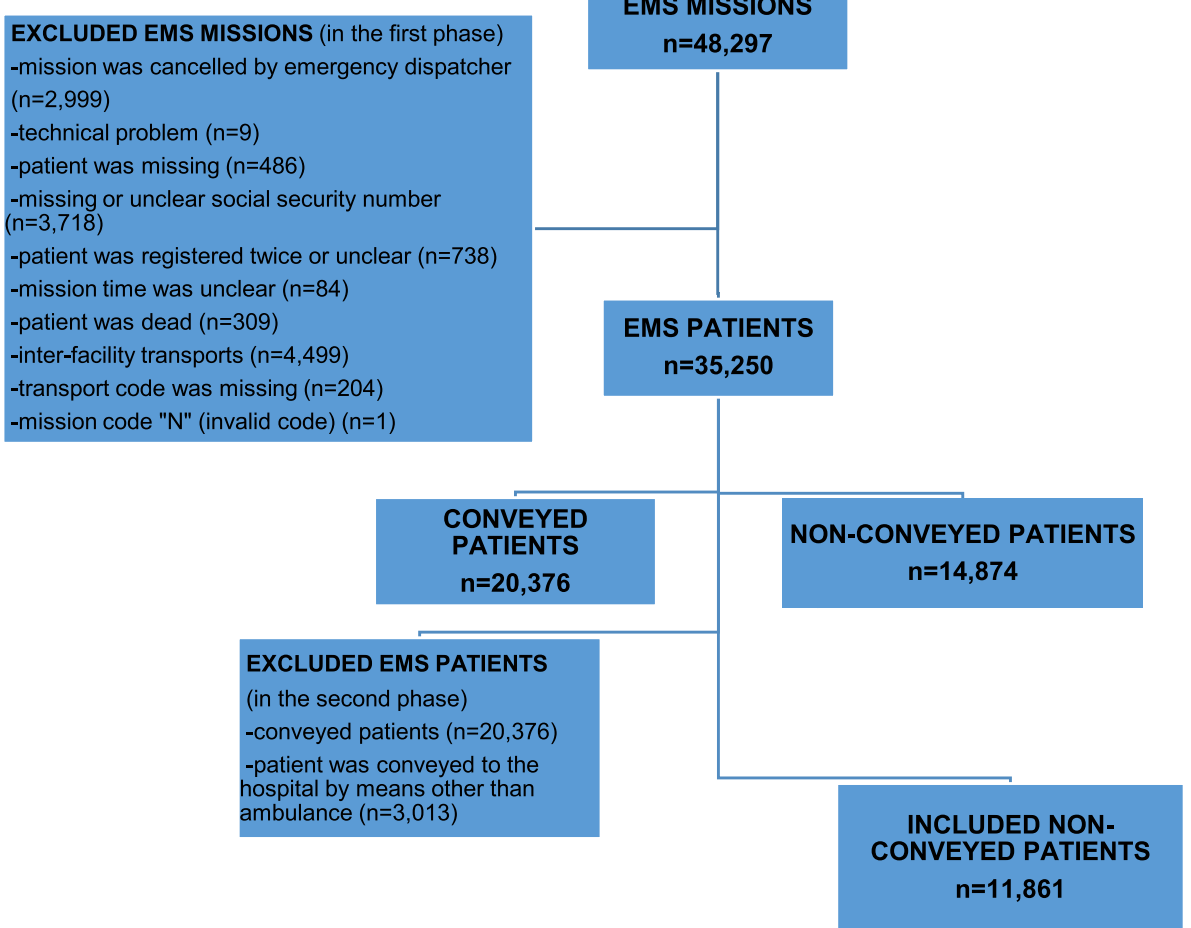

Fig. 2 Flow chart

The Finnish Causes of Death registry data, including death certificates from Statistics Finland [30], were used to identify deceased patients. The deaths were considered for a longer time to gain deeper insight (28 days from initial non-conveyance mission). In the data, the time of death was registered only by date, not by hour. Thus, the $0-24 \mathrm{~h}$ mortality includes deaths that occurred the same and the following day as the initial nonconveyance case. Only unexpected deaths were analyzed; end of life patients were excluded from the analysis because they normally have formal arrangements for dying at home. The death was connected with the last nonconveyance mission. Two experienced emergency physicians (JK and TI) analyzed all cases independently; if the judgement differed, the case was discussed until consensus was reached (JP, JK, and TI). Deceased patients were evaluated as follows: 1) Was the death related to end-oflife care? 2) Did the patient refuse conveyance to the ED or primary health care facility? 3) Was the death credibly connected to the initial non-conveyance case? 4) Would the patient have benefited from conveyance to an ED or primary health care facility?

\section{Outcome measures}

The primary outcomes were EMS re-contact, unscheduled primary health care or ED visit, and hospitalization in $0-24$ and $24-48 \mathrm{~h}$. The secondary outcome was $28-$ day mortality.

\section{Data analysis}

Categorical variables were characterized using frequencies and percentages and continuous variables using medians and interquartile range (IQR). The age groups were defined based on the Finnish national classification provided by Statistics Finland. Distance to nearest primary health care facility or ED was classified for the purposes of the analysis.

Univariate associations between outcome variables and categorical study variables were studied using logistic regression analysis. Multiple logistic regression analysis included variables that were clinically and statistically significant after univariate analysis. The NEWS2 score is suitable only for patients $>16$ years of age, and distance to the nearest primary health care facility or ED measures the same thing as rural-urban classification; therefore, these factors were excluded from the model. Moreover, a non-specific reason for care (ICPC2) as the categorical variable and hospitalization in $24-48 \mathrm{~h}$ and 28-day mortality as dependent variables were infrequent in the data. Thus, these analysis were not performed. Results are presented with univariate and adjusted odds ratios (ORs and aORs) together with 95\% confidence intervals (CIs) and $p$-values. 
All analyses included only patients who did not have missing values for variables included in the model. Statistical analyses were carried out using SAS for Windows version 9.4 (SAS Institute Inc., Cary, NC, USA), and $p<$ 0.05 was considered significant.

\section{Results}

A total of 48,297 EMS missions were identified, with 35,250 EMS missions included for the first-phase analysis. Of these patients, $42 \%(n=14,874)$ were treated and discharged at the scene. Of these non-conveyed patients, 11,861 met the final inclusion criteria for this

Table 1 Characteristics of non-conveyed patients $(N=11,861)$

\begin{tabular}{llll}
\hline & Missing & $\mathbf{n}$ & $\%$ \\
\hline Mission priority & 5 & & \\
A & & 413 & 3.5 \\
B & & 2694 & 22.7 \\
C & & 5534 & 46.7 \\
D & & 3215 & 27.1
\end{tabular}

EMS unit

\begin{tabular}{|c|c|c|c|}
\hline \multicolumn{2}{|l|}{ ALS } & 9627 & 81.2 \\
\hline \multicolumn{2}{|l|}{ BLS } & 2002 & 16.9 \\
\hline \multicolumn{2}{|l|}{ Community Paramedic } & 228 & 1.9 \\
\hline \multicolumn{2}{|l|}{ Field Supervisor } & 4 & 0.03 \\
\hline \multicolumn{2}{|l|}{ Doctor at scene } & 32 & 0.3 \\
\hline \multicolumn{2}{|l|}{ Doctor consulted by phone } & 5118 & 43.2 \\
\hline \multicolumn{4}{|l|}{ ay of week } \\
\hline \multicolumn{2}{|l|}{ Monday } & 1504 & 12.7 \\
\hline \multicolumn{2}{|l|}{ Tuesday } & 1482 & 12.5 \\
\hline \multicolumn{2}{|l|}{ Wednesday } & 1578 & 13.3 \\
\hline \multicolumn{2}{|l|}{ Thursday } & 1635 & 13.8 \\
\hline \multicolumn{2}{|l|}{ Friday } & 1865 & 15.7 \\
\hline \multicolumn{2}{|l|}{ Saturday } & 2014 & 17.0 \\
\hline \multicolumn{2}{|l|}{ Sunday } & 1783 & 15.0 \\
\hline \multirow{2}{*}{\multicolumn{2}{|c|}{ EMS arrival time }} & & \\
\hline & & 6383 & 53.9 \\
\hline \multicolumn{2}{|l|}{ 20:00-08:00 } & 5469 & 46.1 \\
\hline Urban-rural classification & 176 & & \\
\hline \multicolumn{2}{|l|}{ Urban area } & 7198 & 61.6 \\
\hline \multicolumn{2}{|l|}{ Rural area } & 4487 & 38.4 \\
\hline \multirow{2}{*}{\multicolumn{2}{|c|}{$\begin{array}{l}\text { Distance to nearest health care facility } \\
<5 \mathrm{~km}\end{array}$}} & & \\
\hline & & 3871 & 33.1 \\
\hline \multicolumn{2}{|l|}{$5-20 \mathrm{~km}$} & 3941 & 33.7 \\
\hline \multicolumn{2}{|l|}{$21-40 \mathrm{~km}$} & 2578 & 22.1 \\
\hline \multicolumn{2}{|l|}{$>40 \mathrm{~km}$} & 1294 & 11.1 \\
\hline \multicolumn{4}{|c|}{ Median distance 8 km [IQR 3.0-24.6] } \\
\hline \multicolumn{3}{|c|}{ Mission duration: median 52 min [IQR 39-69] } & \\
\hline
\end{tabular}

study (Fig. 2, Table 1). The reasons for non-conveyance are given in Table 2 . The median age of the included patients was 67 (IQR 44-80) years, and 52.6\% were females. Regarding EMS contacts during the study period, $85 \%(n=7887)$ had 1 contact, $14.4 \%(n=1334)$ had $2-6$ contacts, and $0.6 \%(n=60)$ had at least 7 contacts. Overall, $16 \%$ of the patients were under the influence of alcohol. The NEWS2 score was low, with $54.5 \%$ of patients having zero points (Table 3).

After the non-conveyance decision, adverse event rates were as follows: EMS re-contact 0-24h 6.3\%, 24-48 h $2.6 \%$; primary health care facility attendance $0-24 \mathrm{~h}$ 8.3\%, 24-48 h 2.6\%; ED attendance 0-24h 4.4\%, 24-48 h $0.8 \%$; hospitalization after ED contact $0-24 \mathrm{~h} 1.6 \%$, 24-48 h 0.3\%; and death $0-24 \mathrm{~h} 0.1 \%$, 24-48 h $0.03 \%$, within 28 days $1.1 \%$. Some of these patients had multiple types of adverse events, but 4 in $5(83.9 \%$ in $0-24 \mathrm{~h})$ did not have any (Table 4). Reasons for care (ICPC-2) are presented in Table 5.

In the case of EMS re-attendance in $0-24 \mathrm{~h}$, the recontact was related (same ICPC-2 code) to the initial mission in $36.1 \%$ of cases, for a different reason in $50.5 \%$, and the ICPC2 code was missing in $13.4 \%$ of missions. The corresponding figures for EMS re-attendance in $24-48 \mathrm{~h}$ were $29.0,55.0$, and $16.0 \%$, respectively. Of these EMS re-contacts in $0-24 \mathrm{~h}$, in 4 of 5 cases $(80.4 \%)$ the mission priority was non-urgent, ending in a new non-conveyance decision in 39.7\%; the corresponding figures for $24-48 \mathrm{~h}$ are 79.5 and $50.6 \%$, respectively. The NEWS2 points were as follows: at $0-24 \mathrm{~h}, 50.8 \%$ had zero points and $83.3 \%$ had $0-4$ points, whereas at $24-$ $48 \mathrm{~h} 53.0 \%$ had zero points and $85.5 \%$ had $0-4$ points. The median duration of visits to primary health care was $15 \mathrm{~min}$ and $65 \%$ of the patients were discharged from the ED within $24 \mathrm{~h}$. The majority of primary health care or ED ICD10 diagnoses were not mapped to the initial EMS ICPC2 codes. Among the non-conveyed patients, $0.3 \%$ were admitted to an intensive care unit in $0-24 \mathrm{~h}$ $(0.03 \%$ in $24-48 \mathrm{~h})$ and $0.5 \%$ to high dependency units $(0.1 \%$ in $24-48 \mathrm{~h}$; Table 6$)$.

Predictors of adverse events are shown in Table 7. EMS arrival time at night and older patient age were common predictors of many events. Furthermore, EMS re-contact $(0-24 \mathrm{~h})$ was more likely when the patient had refused conveyance than when the EMS had treated

Table 2 Reasons for non-conveyance $(n=11,861)$

\begin{tabular}{lll}
\hline & $\mathbf{n}$ & $\%$ \\
\hline $\begin{array}{l}\text { Treated at scene or there was no need for } \\
\text { conveyance. }\end{array}$ & 10,713 & 90.3 \\
Patients refused conveyance. & 736 & 6.2 \\
Patients were handed over to the police. & 306 & 2.6 \\
Patients received other help, such as homecare. & 106 & 0.9 \\
\hline
\end{tabular}


Table 3 NEWS2 score (age > 16 years)

\begin{tabular}{lll}
\hline NEWS2 score & Clinical risk & $\begin{array}{l}\text { Non-conveyed patients } \\
(\boldsymbol{N}=\mathbf{1 1 , 8 6 1 ,} \text { missing 536) }\end{array}$ \\
\hline Aggregate score $\mathbf{0 - 4}$ & Low & $10,338(91.3)$ \\
Red score; Score of $\mathbf{3}$ in any individual parameter & Low-medium & $714(6.3)$ \\
Aggregate score 5-6 & Medium & $215(1.9)$ \\
Aggregate score $\geq \mathbf{7}$ & High & $58(0.5)$ \\
Median [IQR] & & $0[0-1]$
\end{tabular}

Data are given as $\mathrm{n}(\%)$ unless otherwise noted

the patient at the scene or there was no need for conveyance (aOR 1.79; 95\% CI 1.37 to 2.34). The usage of alcohol (aOR 1.37; 95\% CI 1.10 to 1.71 ) was also associated with EMS re-contact $(0-24 \mathrm{~h})$. Non-urgent mission (aOR 1.49; 95\% CI 1.25 to 1.77 ), ALS unit attendance (aOR 1.43; 95\% CI 1.16 to 1.77 ), and rural area (aOR 1.74; $95 \%$ CI 1.51 to 1.99 ) also increased the likelihood of subsequent visits to a primary health care facility. If the patient was handed over to the police, the likelihood of an ED visit (0-24 h) increased (aOR 2.16; 95\% CI 1.34 to 3.49 ).

In addition, the univariate analyses showed that high NEWS2 score (score of 7 vs. 3 in any individual parameter: OR $3.16,95 \%$ CI 1.54 to 6.48 ; 7 vs. $0-4$ : OR 3.44 , 95\% CI 1.78 to 6.67 ) or a 1-point increase in the NEWS2 score (OR 1.09; 95\% CI 1.04 to 1.15 ) increased the likelihood of EMS re-contact $(0-24 \mathrm{~h})$. There were also significant associations between BLS unit attendance and subsequent ED visit in $0-24 \mathrm{~h}$ (BLS vs. ALS units: OR 1.50; $95 \%$ CI 1.21 to 1.85 ). Longer distance to primary health care or ED predicted subsequent visits to a primary health care facility $(0-24 \mathrm{~h}>40 \mathrm{~km}$ vs. $21-40 \mathrm{~km}$ : OR $1.30,95 \%$ CI 1.05 to $1.61 ;>40 \mathrm{~km}$ vs. $5-20 \mathrm{~km}$ : OR 2.26 , $95 \%$ CI 1.83 to 2.79 ; > $40 \mathrm{~km}$ vs. < $5 \mathrm{~km}$ : OR $1.82,95 \%$ CI 1.48 to $2.24 ; 24-48 \mathrm{~h}>40 \mathrm{~km}$ vs. $21-40 \mathrm{~km}$ : OR $1.54,95 \%$ CI 1.08 to 2.21 ; $>40 \mathrm{~km}$ vs. $5-20 \mathrm{~km}$ : OR 2.42, 95 CI 1.69 to 3.45 ; $>40 \mathrm{~km}$ vs. $<5 \mathrm{~km}$ : OR $2.14,95 \%$ CI 1.51 to 3.03 ). In addition, non-specific reasons for care increased the probability of EMS re-attendance in 24-48 h (OR 1.304; 95\% CI 1.00 to 1.70). These predictors based on univariate analyses did not show any significant associations with other outcomes. Gender ( $p$-value $\geq 0.054)$ and if there was less than an hour to complete a shift $(\mathrm{p}=\geq 0.094)$, did not predict any outcomes in this study.

After exclusion of patients for whom an end of life decision had been made either before or during EMS attendance via telephone consultation with EMS physician ( $n=55$, median age 85 years), there were 126 patients who died within 28 days (Fig. 3). In this group, the mission leading to the non-conveyance decision occurred most often at home $(61 \%, n=77)$. The remaining missions occurred at health care or social service units $(37 \%, n=47)$ and public places $(2 \%, n=2)$. Among the deceased patients, the place of death was at home in $17 \%(n=22)$, at health care or social service units in $81 \%(n=102)$, and in public places in $2 \%(n=2)$. Overall, 10 patients refused conveyance to the ED. The median age of the deceased patients was 83 years. Emergency physicians or primary care physicians were consulted in $51 \%$ of the cases. Based on clinical reevaluation by JP, TI, and JK, $25 \%(n=32)$ of the deaths were related to the initial non-conveyance mission. In four cases $(0.03 \%$ of the initial non-conveyance missions), the non-conveyance decision was not appropriate according to the clinical re-evaluation. In the first case, the patient with symptoms of gastroesophageal reflux had ST-elevation myocardial infarction but a 12-lead ECG had not been recorded. In the three remaining cases, the patients had shortness of breath and swelling of the foot due to coronary disease leading to heart failure, non-specific symptoms due to pneumonia, and aortic dissection with typical back pain. In two of these four cases, a physician had been consulted. In addition, one patient who refused treatment and later died would have clearly benefited from conveyance to the ED.

\section{Discussion}

The main findings of this study were as follows. Firstly, 4 in $5(83.9 \%$ in $0-24 \mathrm{~h})$ of non-conveyed patients had no adverse events after the non-conveyance mission. Secondly, patients were mainly in good condition; the NEWS2 scores were low and duration of visits to primary health care or EDs short. The reasons for the adverse events seem to be different than the reason for the initial EMS mission. Thirdly, $0.03 \%$ of the nonconveyance decisions seem to be related to a patient's death, where re-evaluation showed poor clinical judgement and/or clinical treatment protocol violation.

From the perspective of patient safety, it is important that the majority of non-conveyed patients did not have any subsequent events during the follow-up period, which is in line with previous studies [21,31]. We found that EMS re-contacts, visits to primary health care or ED and hospitalization were relatively rare after nonconveyance missions. Two previous reviews indicate that there are many studies focusing on specific populations 
Table 4 Pathway analyses of adverse events in 0-24 h

\begin{tabular}{|c|c|c|c|c|c|c|c|}
\hline & EMS & Primary health care & ED & Hospitalization & Death & $\mathrm{n}$ & $\%$ \\
\hline Did not have any re-contact & $x$ & $x$ & $x$ & $x$ & $x$ & 9951 & 83.9 \\
\hline Primary health care attendance & $x$ & $\checkmark$ & $x$ & $x$ & $x$ & 805 & 6.8 \\
\hline EMS re-contact & $\checkmark$ & $x$ & $x$ & $x$ & $x$ & 478 & 4.0 \\
\hline ED attendance & $x$ & $x$ & $\checkmark$ & $x$ & $x$ & 233 & 2.0 \\
\hline EMS re-contact and primary health care attendance & $\checkmark$ & $\checkmark$ & $x$ & $x$ & $x$ & 80 & 0.7 \\
\hline EMS re-contact and ED attendance & $\checkmark$ & $x$ & $\checkmark$ & $x$ & $x$ & 74 & 0.6 \\
\hline ED attendance and hospitalization & $x$ & $x$ & $\checkmark$ & $\checkmark$ & $x$ & 73 & 0.6 \\
\hline EMS re-contact, ED attendance and hospitalization & $\checkmark$ & $x$ & $\checkmark$ & $\checkmark$ & $x$ & 65 & 0.6 \\
\hline Primary health care and ED attendance and hospitalization & $x$ & $\checkmark$ & $\checkmark$ & $\checkmark$ & $x$ & 35 & 0.3 \\
\hline Primary health care and ED attendance & $x$ & $\checkmark$ & $\checkmark$ & $x$ & $x$ & 20 & 0.2 \\
\hline Death & $x$ & $x$ & $x$ & $x$ & $\checkmark$ & 17 & 0.1 \\
\hline EMS re-contact, primary health care and ED attendance and hospitalization & $\checkmark$ & $x$ & $\checkmark$ & $\checkmark$ & $x$ & 11 & 0.1 \\
\hline EMS re-contact and death & $\checkmark$ & $x$ & $x$ & $x$ & $\checkmark$ & 9 & 0.1 \\
\hline EMS re-contact, primary health care and ED attendance & $\checkmark$ & $\checkmark$ & $\checkmark$ & $x$ & $x$ & 5 & 0.04 \\
\hline EMS re-contact, ED attendance and death & $\checkmark$ & $x$ & $\checkmark$ & $x$ & $\checkmark$ & 3 & 0.03 \\
\hline Primary health care attendance and death & $x$ & $\checkmark$ & $x$ & $x$ & $\checkmark$ & 2 & 0.02 \\
\hline
\end{tabular}

in which the sample size is small or the follow-up is by telephone, which may lead to bias because the follow-up of a large number of patients may fail $[5,17]$. Thus, comparisons with our findings are challenging. However, the subsequent event rates in this study were roughly the same as in other similar studies [21,31].

Our study indicates that the 24-h period after an EMS visit seems to be critical. The highest incidence of all outcomes occurred within $0-24 \mathrm{~h}$ after the initial nonconveyance mission, which was noted previously [21]. A longer follow-up period could have provided more information, but the likelihood of an adverse event being due to some other reason would have increased.

Our study shows that, in the case of EMS re-contact, primary health care or ED attendance, and hospitalization, the patients were mainly in good condition. The new mission (EMS re-contact) was commonly non-urgent, the patients' NEWS2 scores were low, and almost half of these cases ended in a new non-conveyance decision. The visits to primary health care facilities or EDs were mostly short. On the other hand, 32 patients $(0.3 \%)$ needed intensive care and 62 patients $(0.5 \%)$ were treated in highdependency units after the initial non-conveyance case. These findings are similar to a Swedish study [10]. However, it is difficult to assess whether these patients' critical condition was derived from the EMS's poor clinical judgement and incorrect non-conveyance decision. When comparing the preliminary diagnosis (adjusted ICPC2) to new ICPC2 codes in case of EMS re-contact or discharge diagnoses (ICD10) from primary health care, ED, or after hospitalization, these adverse events were usually not related to the initial non-conveyance mission. In addition, we found that there were many subsequent visits to primary health care, which may be an indication of impaired access to primary health care, especially in the evening and at night.

Our logistic regression model (Table 7) and previous studies [21,32] indicate that older age is a risk factor for adverse outcomes. This may be due to elderly patients' complex symptoms and many comorbidities and medications. We also found that patients' refusal of conveyance and the use of alcohol predicted an EMS re-contact in $0-24 \mathrm{~h}$. One explanation may be that these patients do not know how to handle their problems and an EMS re-call is the easiest choice. Other studies have reported that the refusal is associated with ED visits [33] and alcohol increases the likelihood of non-conveyance [3].

Decision-making at night is challenging [34]. Our results show that EMS arrival at night increases the likelihood of 3 in 4 primary outcomes of this study. However, the end of a work shift was not associated with recontacts, which may indicate that EMS providers consider the patient's needs even though the shift is close to its end. However, EMS arrival at night, non-urgent mission, ALS unit, rural area, and longer distance to a health care facility or ED were related to subsequent visits to primary health care. There is a possibility that this demonstrates appropriate use of health care resources to avoid unnecessary conveyance to the ED. Geographic variation in the EMS context is high [35], but the impact of geography on a patient's outcome is unclear. However, the on-scene time is reported to be high in rural areas [36] and in the case of nonconveyance [3]. Understandably, visits to primary health 
Table 5 The initial ICPC2-codes of non-conveyed patients before subsequent events

\begin{tabular}{|c|c|c|c|c|c|c|c|}
\hline \multicolumn{4}{|c|}{ EMS re-contacts $0-24 \mathrm{~h}(n=652$, missing 73$)$} & \multicolumn{4}{|c|}{ EMS re-contacts $24-48 \mathrm{~h}(n=262$, missing 31$)$} \\
\hline \multicolumn{2}{|l|}{ ICPC2 } & $n$ & $\%$ & ICPC2 & & $\mathrm{n}$ & $\%$ \\
\hline A04 & Weakness/tiredness, general & 99 & 15.2 & A04 & Weakness/tiredness, general & 49 & 18.7 \\
\hline P16 & Acute alcohol abuse & 80 & 12.3 & A97 & No disease & 34 & 13.0 \\
\hline A97 & No disease & 78 & 12.0 & P16 & Acute alcohol abuse & 28 & 10.7 \\
\hline L02 & Back symptom/complaint & 39 & 6.0 & L02 & Back symptom/complaint & 17 & 6.5 \\
\hline R02 & Shortness of breath/dyspnea & 38 & 5.8 & P29 & Psychological symptom/complaint other & 15 & 5.7 \\
\hline D01 & Acute abdomen & 28 & 4.3 & A11 & Chest pain & 13 & 5.0 \\
\hline A11 & Chest pain & 22 & 3.4 & R02 & Shortness of breath/dyspnea & 10 & 3.8 \\
\hline P29 & Psychological symptom/complaint other & 22 & 3.4 & D01 & Acute abdomen & 8 & 3.1 \\
\hline $\mathrm{A} 01$ & Pain general & 19 & 2.9 & N17 & Vertigo/dizziness & 7 & 2.7 \\
\hline N07 & Convulsion/seizure & 17 & 2.6 & N01 & Headache & 6 & 2.3 \\
\hline \multicolumn{4}{|c|}{$\begin{array}{l}\text { Visit to primary health care } 0-24 \mathrm{~h} \\
(n=877, \text { missing } 81)\end{array}$} & \multicolumn{4}{|c|}{$\begin{array}{l}\text { Visit to primary health care } 24-48 \mathrm{~h} \\
(n=263, \text { missing } 23)\end{array}$} \\
\hline \multicolumn{2}{|c|}{ ICPC2 } & $n$ & $\%$ & \multicolumn{2}{|c|}{ ICPC2 } & $\mathrm{n}$ & $\%$ \\
\hline A04 & Weakness/tiredness, general & 118 & 13.5 & A04 & Weakness/tiredness, general & 38 & 14.5 \\
\hline L02 & Back symptom/complaint & 52 & 5.9 & A97 & No disease & 21 & 8.0 \\
\hline D01 & Acute abdomen & 52 & 5.9 & D01 & Acute abdomen & 18 & 6.8 \\
\hline A11 & Chest pain & 49 & 5.6 & $\mathrm{~K} 80$ & Other cardiac arrhythmia & 16 & 6.1 \\
\hline A97 & No disease & 48 & 5.5 & L02 & Back symptom/complaint & 14 & 5.3 \\
\hline P16 & Acute alcohol abuse & 33 & 3.8 & A11 & Chest pain & 12 & 4.6 \\
\hline N17 & Vertigo/dizziness & 32 & 3.7 & A01 & Pain general & 11 & 4.2 \\
\hline A03 & Fever & 30 & 3.4 & N17 & Vertigo/dizziness & 9 & 3.4 \\
\hline K85 & High blood pressure & 29 & 3.3 & P29 & Psychological symptom/complaint other & 9 & 3.4 \\
\hline A01 & Pain general & 23 & 2.6 & P16 & Acute alcohol abuse & 8 & 3.0 \\
\hline \multicolumn{4}{|c|}{ Visit to ED $0-24 \mathrm{~h}(n=438$, missing 81$)$} & \multicolumn{4}{|c|}{ Visit to ED $24-48 \mathrm{~h}(n=78$, missing 8$)$} \\
\hline \multicolumn{2}{|c|}{ ICPC2 } & $n$ & $\%$ & \multicolumn{2}{|c|}{ ICPC2 } & $\mathrm{n}$ & $\%$ \\
\hline A04 & Weakness/tiredness, general & 49 & 11.2 & A04 & Weakness/tiredness, general & 11 & 14.1 \\
\hline A97 & No disease & 46 & 10.5 & L02 & Back symptom/complaint & 8 & 10.3 \\
\hline D01 & Acute abdomen & 28 & 6.4 & A97 & No disease & 6 & 7.7 \\
\hline L02 & Back symptom/complaint & 27 & 6.2 & A11 & Chest pain & 6 & 7.7 \\
\hline P16 & Acute alcohol abuse & 25 & 5.7 & D01 & Acute abdomen & 4 & 5.1 \\
\hline P29 & Psychological symptom/complaint other & 15 & 3.4 & P16 & Acute alcohol abuse & 3 & 3.9 \\
\hline A01 & Pain general & 15 & 3.4 & A03 & Fever & 3 & 3.9 \\
\hline L17 & Foot/toe symptom/complaint & 13 & 3.0 & A06 & Fainting/syncope & 3 & 3.9 \\
\hline $\mathrm{A} 03$ & Fever & 12 & 2.7 & P29 & Psychological symptom/complaint other & 2 & 2.6 \\
\hline A11 & Chest pain & 11 & 2.5 & A92 & Allergy/allergic reaction NOS & 2 & 2.6 \\
\hline \multicolumn{4}{|c|}{ Hospitalization $0-24 \mathrm{~h}(n=155$, missing 29$)$} & \multicolumn{4}{|c|}{ Hospitalization $24-48 \mathrm{~h}(n=26$, missing 1$)$} \\
\hline \multicolumn{2}{|c|}{ ICPC2 } & n & $\%$ & \multicolumn{2}{|c|}{ ICPC2 } & $\mathrm{n}$ & $\%$ \\
\hline A04 & Weakness/tiredness, general & 24 & 15.5 & A04 & Weakness/tiredness, general & 5 & 17.2 \\
\hline A97 & No disease & 16 & 10.3 & A11 & Chest pain & 2 & 6.9 \\
\hline L02 & Back symptom/complaint & 11 & 7.1 & A97 & No disease & 2 & 6.9 \\
\hline P16 & Acute alcohol abuse & 10 & 6.5 & A87 & Complication of surgical procedure & 2 & 6.9 \\
\hline L17 & Foot/toe symptom/complaint & 10 & 6.5 & D01 & Acute abdomen & 2 & 6.9 \\
\hline D01 & Acute abdomen & 8 & 5.2 & L02 & Back symptom/complaint & 2 & 6.9 \\
\hline A11 & Chest pain & 6 & 3.9 & A06 & Fainting/syncope & 2 & 6.9 \\
\hline A03 & Fever & 6 & 3.9 & L04 & Chest symptom/complaint & 2 & 6.9 \\
\hline P29 & Psychological symptom/complaint other & 6 & 3.9 & A01 & Pain general & 1 & 3.5 \\
\hline A01 & Pain general & 5 & 3.2 & K74 & Ischemic chest pain & 1 & 3.5 \\
\hline
\end{tabular}


Table 6 Characteristics of study outcomes

\begin{tabular}{|c|c|c|c|c|}
\hline & $0-24 h, n$ & $0-24 h, \%$ & 24-48 h, n & $\begin{array}{l}24-48 h \text {, } \\
\%\end{array}$ \\
\hline EMS re-contacts & 725 & 6.3 & 293 & 2.6 \\
\hline \multicolumn{5}{|l|}{ Mission priority } \\
\hline non-urgent & 583 & 80.4 & 222 & 75.8 \\
\hline urgent & 142 & 19.6 & 71 & 24.2 \\
\hline ended in a non-conveyance decision & 288 & 39.7 & 148 & 50.6 \\
\hline \multicolumn{5}{|l|}{ NEWS2 points } \\
\hline zero & 366 & 50.8 & 156 & 53.8 \\
\hline $0-4$ & 600 & 83.3 & 248 & 85.5 \\
\hline \multicolumn{5}{|c|}{ EMS re-contact association with initial non-conveyance mission } \\
\hline ICPC2 code same & 262 & 36.1 & 85 & 29.0 \\
\hline ICPC2 code different & 366 & 50.5 & 161 & 55.0 \\
\hline ICPC2 code missing & 97 & 13.4 & 47 & 16.0 \\
\hline Visit to primary health care facility & 958 & 8.3 & 286 & 2.6 \\
\hline \multicolumn{5}{|c|}{ Visit duration: median 15 min [IQR 0-20] (0-24 h) and 20 min [IQR 0-30] (24-48 h) } \\
\hline \multicolumn{5}{|c|}{ Primary health care visit associated with initial non-conveyance mission } \\
\hline ICPC2 code mapped to ICD10 code & 95 & 9.9 & 25 & 8.8 \\
\hline ICPC2 code does not map to ICD10 code & 785 & 81.7 & 237 & 83.2 \\
\hline ICPC2 code mapped to ICD10 category & 154 & 16.0 & 41 & 14.4 \\
\hline ICPC2 code does not map to ICD10 category & 726 & 75.5 & 221 & 77.5 \\
\hline ICPC2 code or ICD10 code missing & 81 & 8.4 & 23 & 8.1 \\
\hline Visit to ED & 519 & 4.4 & 86 & 0.8 \\
\hline \multicolumn{5}{|l|}{ Visit duration: $65 \%$ of visits less than 1 day } \\
\hline \multicolumn{5}{|c|}{ ED visit associated with initial non-conveyance mission } \\
\hline ICPC2 code mapped to ICD10 code & 63 & 12.1 & 10 & 11.8 \\
\hline ICPC2 code does not map to ICD10 code & 376 & 72.3 & 67 & 78.8 \\
\hline ICPC2 code mapped to ICD10 category & 85 & 16.3 & 17 & 20.0 \\
\hline ICPC2 code does not map to ICD10 category & 354 & 68.1 & 60 & 70.6 \\
\hline ICPC2 code or ICD10 code missing & 81 & 15.6 & 8 & 9.4 \\
\hline Hospitalization & 184 & 1.6 & 30 & 0.3 \\
\hline \multicolumn{5}{|c|}{ Visit duration: median 2 days [IQR 1-4.5] (0-24 h) and 1 day [IQR 1-2] (24-48 h) } \\
\hline Intensive care & 32 & 0.3 & 3 & 0.03 \\
\hline High dependency unit & 62 & 0.5 & 12 & 0.1 \\
\hline \multicolumn{5}{|c|}{ Hospitalization associated with initial non-conveyance mission } \\
\hline ICPC2 code mapped to ICD10 code & 6 & 3.3 & 5 & 16.7 \\
\hline ICPC2 code does not map to ICD10 code & 178 & 96.7 & 25 & 83.3 \\
\hline ICPC2 code mapped to ICD10 category & 16 & 8.7 & 7 & 23.3 \\
\hline ICPC2 code does not map to ICD10 category & 168 & 91.3 & 23 & 76.6 \\
\hline ICPC2 code or ICD10 code missing & 29 & 15.8 & 1 & 3.3 \\
\hline
\end{tabular}

care were related to non-urgent missions. In contrast, it seems that EMSs can safely discharge urgent missions such as hypoglycemia and other chronic diseases at the scene after appropriate assessment and treatment. Previous studies have shown that non-conveyance is challenging and requires competence [5, 34]. Indeed, there are a number of factors that are related to nonconveyance decisions [3, 8, 37-39]. Our study demonstrated that ALS units are associated with re-contact in primary health care. This may be due to the longer 


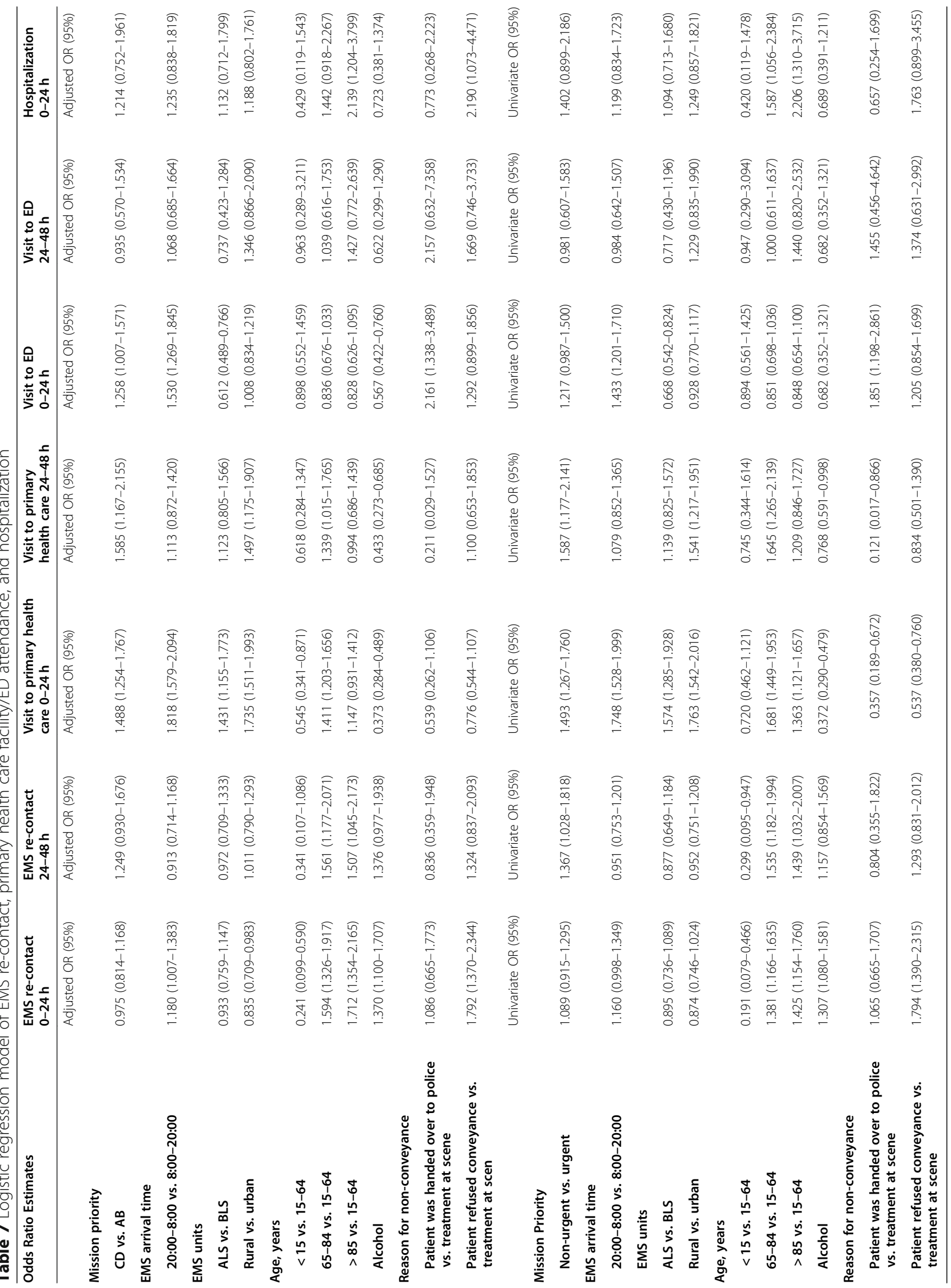




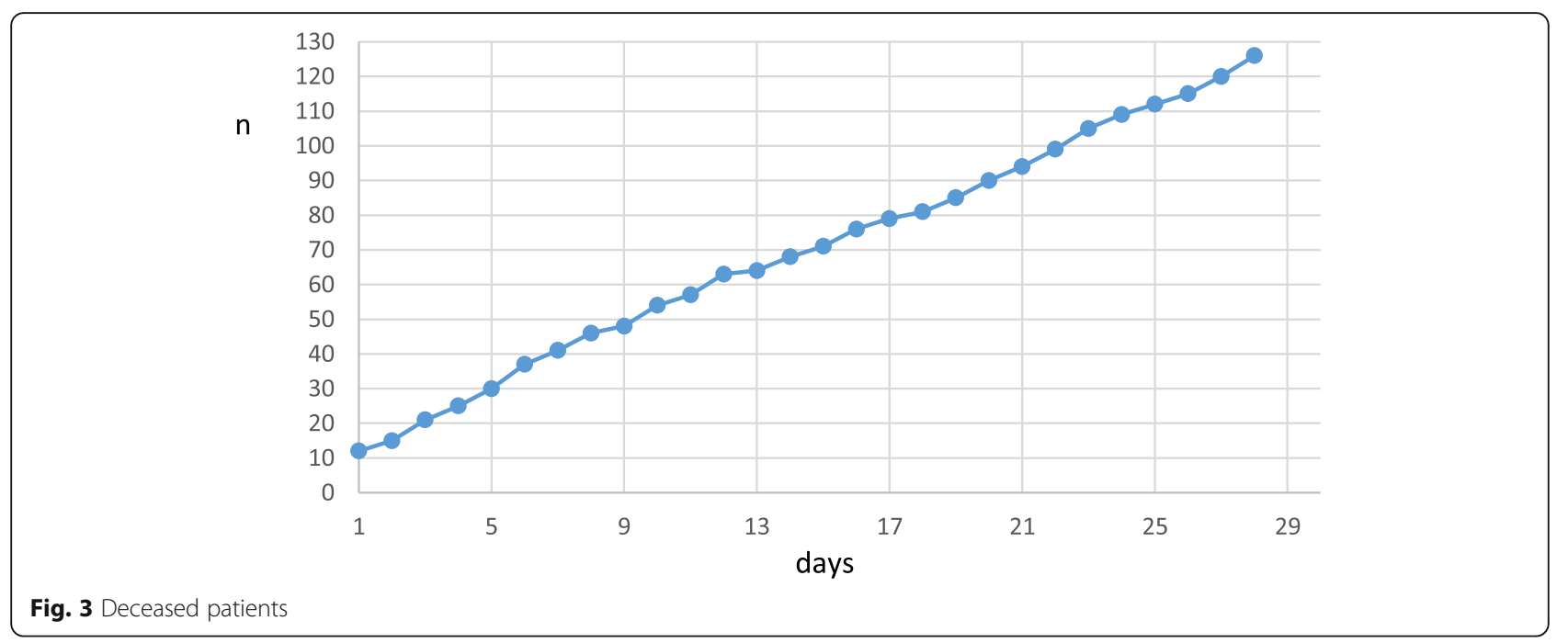

education of EMS care providers in ALS units, which may be associated with more appropriate decisionmaking related to the use of primary health care and ED resources. On the other hand, based on the univariate analyses, BLS units increased the risk of subsequent ED visits. This raises the question of whether these visits are related to the BLS units' competence. However, more studies are needed.

Moreover, an Australian study indicated that, when the EMS discharged patients at the scene, there was an increased risk of adverse events compared to patients discharged from the ED [21]. Notably, subsequent contacts with health care do not automatically mean that patient safety is compromised [5, 30].

Abnormal vital signs have been found as a common predictor of adverse events after EMS non-conveyance [21]. We found that, if the patient's NEWS2 score increases by 1 point or the score is high ( $>7$ points), the risk of EMS re-contact increases. Non-specific complaints lead to a number of adverse outcomes in both the EMS context and EDs [19, 20,40]. Surprisingly, we did not find similar results. Based on univariate analyses, non-specific complaints were only related to EMS recontact in $24-48 \mathrm{~h}$.

\section{Limitations}

This study has several limitations, three of which were described previously (excluded patients, the use of adjusted ICPC2 classification, and NEWS2 score calculation) [3].

The register of ED visits included the date, but the exact visit time was mainly missing. Thus, the initial non-conveyance case was judged to have occurred first and the $0-24 \mathrm{~h}$ ED visit to have occurred on the same day or the following day. Furthermore, the register of visits to primary health care includes chronic disease monitoring. Therefore, the rate of visits to primary health care and EDs for real adverse events after the non-conveyance mission may be lower. On the other hand, some patients may have sought further care at private clinics, but all patients with severe or even moderate deterioration would have been sent to an ED.

The reasons for care (adjusted ICPC2) were compared to the discharge diagnoses (ICD10) from the primary health care facilities or EDs or to diagnoses after hospitalization in order to determine whether these events were related to the initial non-conveyance mission. Notably, the ICPC2 chosen by EMSs is based on symptoms and signs present at the time of the EMS contact. The time between ICPC2 and discharge diagnosis, further examination, and the treatment given may affect the discharge diagnosis. Thus, the real rate of adverse events due to the same reason as the initial nonconveyance case may be higher.

Only unexpected deaths were analyzed, and therefore patients with end of life decisions were excluded. However, it is possible that this approach did not identify all of these patients due to missing information. When assessing the risk factors for adverse events, 28-day mortality and hospitalization in $24-48 \mathrm{~h}$ were excluded from our multivariable logistic regression model as dependent variables because these events were very rare in our data set.

In Finland, EMSs and EDs are encouraged to plan emergency patient pathways together. Therefore, triaging and assessing the need for conveyance and nonconveyance decisions are commonly made by the EMS. This practice and the level and scope of education differs between countries; therefore, the generalizability of the results may be limited [23]. 


\section{Conclusion}

Most non-conveyance patients did not have adverse events in the follow-up period. In the case of EMS recontact or visits to a primary health care facility or ED and hospitalization, the patients were mainly in good condition and the reason was often something other than the initial non-conveyance mission. A small proportion of non-conveyed patients were later in critical condition; deaths were very infrequent. From a patient safety perspective, the subsequent $24 \mathrm{~h}$ after a nonconveyance decision are critical. EMS non-conveyance seems to be a safe and rational use of limited resources and, therefore, is a solution that reduces unnecessary patient conveyance to EDs.

\section{Abbreviations}

EMS: Emergency medical services; ED: Emergency Department;

ALS: Advanced Life Support; BLS: Basic Life Support; NEWS2: National Early Warning Score

\section{Acknowledgements}

The authors acknowledge Niina Käyhkö and Venla Aaltonen for the geographical analyses and Hans Moen, Sanna Salanterä, and Nischal Guragain for the machine learning part of the NEWS2 calculation (from University of Turku).

\section{Authors' contributions}

JP and MK had full access to all the data in the study and take responsibility for the integrity of the data and the accuracy of the data analysis. JP, JK and $\mathrm{TI}$ analysed the deceased patients, like mentioned before. All authors contributed to the design of the study, interpreted the results, revised the article, and approved the final manuscript. JP takes responsibility for the paper as a whole.

\section{Funding}

JP was supported by scientific research grants from the University of Turku (Doctoral Programme in Clinical Research (DPCR) / Medicine) and the Foundation of EMS support.

\section{Availability of data and materials}

The data of this study is not available due to patients' privacy.

\section{Declarations}

\section{Ethics approval and consent to participate}

Written Ethical approval was received from the Ethics Committee of the Hospital District of Southwest Finland (Approval no: DNRO 70 /1802/2018). The use of patient identifiable data was approved by the Finnish Institute for Health and Welfare and by the Data Protection Ombudsman (part of research permission).

\section{Consent for publication}

Not applicable.

\section{Competing interests}

The authors declare that they have no competing interests.

\section{Author details}

${ }^{1}$ Department of Clinical Medicine, University of Turku and Turku University of Applied Sciences, Turku, Finland. ${ }^{2}$ Centre for Prehospital Emergency Care, Kuopio University Hospital and University of Eastern Finland, Kuopio, Finland. ${ }^{3}$ Department of Biostatistics, University of Turku, Turku, Finland. ${ }^{4}$ Emergency Medical Services, Turku University Hospital and University of Turku, Turku, Finland.
Received: 18 June 2021 Accepted: 27 September 2021

Published online: 09 October 2021

\section{References}

1. Andrew $E$, Nehme Z, Cameron P, Smith K. Drivers of increasing emergency ambulance demand. Prehosp Emerg Care. 2020;24(3):385. https://doi.org/1 $0.1080 / 10903127.2019 .1635670$

2. Lowthian JA, Cameron PA, Stoelwinder JU, Curtis A, Currell A, Cooke MW, et al. Increasing utilisation of emergency ambulances. Aust Health Rev. 2011;35(1):63-9. https://doi.org/10.1071/AH09866.

3. Paulin J, Kurola J, Salanterä S, Moen H, Guragain N, Koivisto M, et al. Changing role of EMS -analyses of non-conveyed and conveyed patients in Finland. Scand J Trauma Resusc Emerg Med. 2020;28(1):45. https://doi.org/1 0.1186/s13049-020-00741-w.

4. Fisher JD, Freeman $K$, Clarke A, Spurgeon P, Smyth M, Perkins GD, et al. Patient safety in ambulance services: a scoping review. Health Serv Deliv Res. 2015;3(21):21-250. https://doi.org/10.3310/hsdr03210.

5. Ebben RHA, Vloet RF, Tönjes NW, Loef J, Pelgrin T, Hoogeveen M, et al. A patient-safety and professional perspective on non-conveyance in ambulance care: a systematic review. Scand J Trauma Resusc Emerg Med. 2017;25(1):71. https://doi.org/10.1186/s13049-017-0409-6.

6. Pekanoja S, Hoikka M, Kyngäs H, Elo S. Non-transport emergency medical service missions - a retrospective study based on medical charts. Acta Anaesthesiol Scand. 2018:62(5):701-8. https://doi.org/10.1111/aas.13071.

7. Hoikka M, Silfast T, Ala-Kokko TI. A high proportion of prehospital emergency patients are not transported by ambulance: a retrospective cohort study in northern Finland. Acta Anaesthesiol Scand. 2017;61(5):549_ 56. https://doi.org/10.1111/aas.12889.

8. Oosterwold J, Sagel D, Berben S, Roodbol B, Broekhuis M. Factors influencing the decision to convey or not to convey elderly people to the emergency department after emergency ambulance attendance: a systematic mixed studies review. BMJ Open. 2018;30(8):e021732.

9. Lederman J, Lindström V, Elmqvist C, Löfvenmark C, Djärv T. Nonconveyance in the ambulance service: a population-based cohort study in Stockholm. Sweden BMJ Open. 2020;10(7):e036659. https://doi.org/10.1136/ bmjopen-2019-036659.

10. Magnusson C, Herlitz J, Axelsson C. Patient characteristics, triage utilisation, level of care, and outcomes in an unselected adult patient population seen by the emergency medical services: a prospective observational study. BMC Emergency Medicine. 2020;20(1):7. https://doi.org/10.1186/s12873-020-0302-x.

11. Vloet LCM, de Kreek A, van der Linden WMC, van Spijk A, Theunissen AH, van Wnarooij $\mathrm{M}$, et al. A retrospective comparison between non-conveyed and conveyed patients in ambulance care. Scand J Trauma Resusc Emerg Med. 2018;26(1):91. https://doi.org/10.1186/s13049-018-0557-3.

12. Khorram-Manesh A, Lennquist Montan K, Hedelin A, Kihlgren M, Örtenwall P. Prehospital triage, discrepancy in priority-setting between emergency medical dispatch Centre and ambulance crews. Eur J Trauma Emerg Surg. 2011;37(1):73-8. https://doi.org/10.1007/s00068-010-0022-0.

13. Royal College of Physicians. National Early Warning Score (NEWS)2: Standardising the assessment of acute-illness severity in the NHS. Updated report of a working party. London: RCP; 2017. https://www.rcplondon.ac.uk/ projects/outputs/national-early-warning-score-news-2. Accessed 3 March 2021

14. Patel R, Nugawela D, Edwards HB, Richards A, Le Roux H, Pullyblank A, et al. Can early warning scores identify deteriorating patients in pre-hospital settings? A systematic review. Resuscitation. 2018:132:101-11. https://doi. org/10.1016/j.resuscitation.2018.08.028.

15. Williams TA, Tohira H, Finn J, Perkins GD, Ho KM. The ability of early warning scores (EWS) to detect critical illness in the prehospital setting: A systematic review. Resuscitation. 2016;102:35-43. https://doi.org/10.1016/j. resuscitation.2016.02.011

16. Bigham B, Buick JE, Brooks SC, Morrison M, Shojania KG, Morrison LJ. Patient safety in emergency medical services: A systematic review of the literature. Prehosp Emerg Care. 2012;16(1):20-35. https://doi.org/10.3109/10903127.2 011.621045

17. Blodgett JM, Robertson DJ, Pennington E, Ratcliffe D, Rockwood K. Alternatives to direct emergency department conveyance of ambulance patients: a scoping review of the evidence. Scand J Trauma Resusc Emerg Med. 2021;29(1):4. https://doi.org/10.1186/s13049-020-00821-x.

18. Koivulahti O, Tommila M, Haavisto E. The accuracy of preliminary diagnoses made by paramedics - a cross-sectional comparative study. Scand J Trauma Resusc Emerg Med. 2020;28(1):70. https://doi.org/10.1186/s13049-020-00761-6. 
19. Nielsen FV, Nielsen MR, Amstrup J, Lorenzen ID, Kløjgaard TA, Færk E, et al Non-specific diagnoses are frequent in patients hospitalized after calling 112 and their mortality is high - a register-based Danish cohort study. Scand J Trauma Resusc Emerg Med. 2020;28(1):69. https://doi.org/10.1186/ s13049-020-00768-z.

20. Ivic R, Kurland R, Vicente V, Castren M, Bohm K. Serious conditions among patients with non-specific chief complaints in the prehospital setting: a retrospective cohort study. Scand J Trauma Resusc Emerg Med. 2020;28(1): 74. https://doi.org/10.1186/s13049-020-00767-0.

21. Tohira $H$, Fatovich $T$, Williams $T A$, Bremner $A B$, Arends $G$, Rogers $I R$, et al. Is it appropriate for patients to be discharged at the scene by paramedics? Prehosp Emerg Care. 2016;20(4):539-49. https://doi.org/10.3109/10903127.2 015.1128028.

22. Yeung T, Shannon B, Perillo S, Nehme Z, Jennings P, Olauseen A. Review article: outcomes of patients who are not transported following ambulance attendance: A systematic review and meta-analysis. Emerg Med Australas. 2019;31(3):321-31. https://doi.org/10.1111/1742-6723.13288

23. Health Care Act. https://www.finlex.fi/en/laki/kaannokset/2010/en2010132 6 20131293.pdf. Accessed 24 March 2021.

24. World Organization of Family Doctors (WONCA). International Classification of Primary Care 2016.https://www.globalfamilydoctor.com/site/DefaultSite/ filesystem/documents/Groups/WICC/International\%20Classification\%20of\%2 OPrimary\%20Care\%20Dec16.pdf. Accessed 15 Sept 2021.

25. WHO. International Classification of Primary Care, Second edition (ICPC-2). 2003. https://www.who.int/standards/classifications/other-classifications/ international-classification-of-primary-care. Accessed 15 Sept 2021

26. The Nordic Emergency Medical Services. Project on data collection and benchmarking 2014-2018. Report Ordening NR IS-2750 2018. https://www. landlaeknir.is/servlet/file/store93/item36845/Nordic\%20EMS\%20benchma rking\%20report\%202014-2018.pdf. Accessed 15 Sept 2021.

27. THL. The adjusted ICPC2 classification for Emergency medical services. https://koodistopalvelu.kanta.fi/codeserver/pages/classification-view-page. $x$ html? classificationKey=3784\&versionKey=4285. Accessed 15 Sept 2021.

28. Register of Primary Health Care Visits. https:/thl.fi/en/web/thlfi-en/statistics/ information-on-statistics/register-descriptions/register-of-primary-health-ca re-visits\#name. Accessed 10 March 2021.

29. Care Register for Health Care. https://thl.fi/en/web/thlfi-en/statistics/informa tion-on-statistics/register-descriptions/care-register-for-health-care. Accessed 11 March 2021.

30. Official Statistics of Finland (OSF): Causes of death [e-publication]. ISSN= 1799-5078. Helsinki: Statistics Finland. http://www.stat.fi/til/ksyyt/index_en. htm. Accessed 20 March 2021.

31. Coster J, O'Cathain A, Jacques R, Crum A, Siriwardena AN, Turner J. Outcomes for Patients Who Contact the Emergency Ambulance Service and Are Not Transported to the Emergency Department: A Data Linkage Study. Prehosp Emerg Care. 2019;23(4):566-77. https://doi.org/10.1080/10903127.2 018.1549628.

32. Vilke GM, Sardar W, Fisher R, Dunford JD, Chan TC. Follow-up of elderly patients who refuse transport after accessing 9-1-1. Prehosp Emerg Care. 2002;6(4):391-5. https://doi.org/10.1080/10903120290938003.

33. Knight S, Olson LM, Cook LJ, Mann NC, Corneli HM, Dean JM. Against all advice: an analysis of out-of-hospital refusals of care. Ann Emerg Med. 2003; 42(5):689-96. https://doi.org/10.1016/S0196-0644(03)00524-9.

34. O'Hara R, Johnson M, Siriwardena AN, Weyman A, Turner J, Shaw D, et al. A qualitative study of systemic influences on paramedic decision making: care transitions and patient safety. J Health Serv Res Policy. 2015 Jan;20(1 Suppl): 45-53. https://doi.org/10.1177/1355819614558472.

35. Hanchate AD, Paasche-Orlow MK, Dyer KS, Baker WE, Feng C, Feldman J. Geographic Variation in Use of Ambulance Transport to the Emergency Department. Ann Emerg Med. 2017;70:533-543.e7.

36. Alanazy ARM, WarkS FJ, Nagle A. Factors Impacting Patient Outcomes Associated with Use of Emergency Medical Services Operating in Urban Versus Rural Areas: A Systematic Review. Int J Environ Res Public Health. 2019;16(10):1728. https://doi.org/10.3390/ijerph16101728.

37. Forsgärde ES, Elmqvist C, Fridlund B, Svensson A, Andersson A, Rööst M. Patients' aged $\geq 65$ years dispositions during ambulance assignments, including factors associated with non-conveyance to hospital: a longitudinal and comparative study. BMJ Open. 2020;10(11):e038885. https://doi.org/1 0.1136/bmjopen-2020-038885.
38. O'Cathain A, Jacques R, Stone T, Turner J. Why do ambulance services have different non-transport rates? A national cross sectional study. PLoS One. 2018;13(9):e0204508. https://doi.org/10.1371/journal.pone.0204508.

39. Knowles E, Bishop-Edwards L, O'Cathain A. Exploring variation in how ambulance services address non-conveyance: a qualitative interview study. BMJ Open. 2018;8(11):e024228. https://doi.org/10.1136/bmjopen-2018-024228.

40. Kemp K, Mertanen R, Lääperi M, Niemi-Murola L, Lehtonen L, Castren M. Nonspesific complaints in the emergency department - a systematic review. Scand J Trauma Resusc Emerg Med. 2020;28(1):6. https://doi.org/1 0.1186/s13049-020-0699-y.

\section{Publisher's Note}

Springer Nature remains neutral with regard to jurisdictional claims in published maps and institutional affiliations.
Ready to submit your research? Choose BMC and benefit from:

- fast, convenient online submission

- thorough peer review by experienced researchers in your field

- rapid publication on acceptance

- support for research data, including large and complex data types

- gold Open Access which fosters wider collaboration and increased citations

- maximum visibility for your research: over $100 \mathrm{M}$ website views per year

At BMC, research is always in progress.

Learn more biomedcentral.com/submissions 